GUEST EDITORIAL

\section{Thalassaemia (part 1)}

The thalassaemias are a group of inherited blood disorders characterised by decreased or absent globin chain synthesis. The clinical syndrome of thalassaemia was first described in 1925 by Thomas Cooley, a paediatrician from Detroit. He documented a constellation of findings, including splenomegaly, severe anaemia and bony deformities in children of Italian and Greek descent, which became known as Cooley's anaemia. The syndrome was subsequently termed thalassaemia, derived from the Greek words thalassa and haima, which translate as sea and blood, respectively, as a high prevalence was noted in areas adjacent to the Mediterranean Sea.

Thalassaemia is the most common monogenic disorder worldwide. As with other inherited haemolytic conditions, the geographical distribution of the condition has a high degree of overlap with areas endemic to malaria, this being a consequence of partial protection of heterozygotes (thalassaemia carriers) against malaria. It is this survival advantage against malaria and consequent natural selection of the heterozygous form that is responsible for elevating and maintaining such high gene frequencies.

The proposed mechanisms of protection may be categorised as immune related or cellular, and include better immune clearance, reduced survival of the malarial parasite within red blood cells and diminished parasite capacity for invasion of red blood cells. The thalassaemias are most commonly encountered among people of Italian, Greek, Middle Eastern, South Asian and African descent. Thalassaemia, as well as other inherited haemolytic conditions, is increasingly encountered in countries not endemic to malaria because of migration. ${ }^{[1]}$

Classification of thalassaemia is based on the globin chain that is deficient. For instance, in $\alpha$-thalassaemia there is underproduction of $\alpha$-globin chains, and in $\beta$-thalassemia there is underproduction of $\beta$-globin chains. Likewise, in $\gamma$ - and $\delta$-thalassaemia, there is underproduction of $\gamma$ - and $\delta$-globin chains, respectively. The clinical phenotype depends on the number of globin genes affected and varies from the asymptomatic state to severe haemolytic anaemia. Furthermore, co-inheritance of $\mathrm{Hb}$ variants is not uncommon, e.g. sickle cell disease or $\mathrm{HbE}$ may be co-inherited with $\alpha$ - or $\beta$-thalassaemia, which results in a diverse set of clinical phenotypes.

The advent of next-generation sequencing (NGS) represents a significant advance in the diagnosis of inherited red cell disorders. Apart from elucidating genetic defects, NGS allows for simultaneous detection of co-existing abnormalities, providing greater insight into genotypephenotype associations and aiding the course of genetic counselling.
Human $\mathrm{Hb}$ is a tetrameric molecule that is comprised of two $\alpha$ - and two non- $\alpha$-globin chains. Postnatally, three $\mathrm{Hb}$ subtypes exist, viz. $\operatorname{HbA}\left(\alpha_{2}, \beta_{2}\right), \operatorname{HbF}\left(\alpha_{2}, \gamma_{2}\right)$ and $\operatorname{HbA} 2\left(\alpha_{2}, \delta_{2}\right)$, each comprising $>95 \%,<2 \%$ and $2.4-3.7 \%$ of the total $\mathrm{Hb}$, respectively. These proportions are reached at the end of the first year of life. Since $\mathrm{HbA}$ constitutes the major fraction of total $\mathrm{Hb}$, the $\alpha$ - and $\beta$-thalassaemias represent the bulk of clinically significant thalassaemias, and are therefore the focus of this 2-part CME series. In this issue (part 1), ${ }^{[2]}$ the discourse centres around epidemiology, pathophysiology, clinical exposition and diagnosis. Management issues are discussed in the forthcoming issue (part 2).

The authors are indeed grateful for the opportunity to discuss the topic of thalassaemia, a subject that is often not clearly understood owing to variable genotype-phenotype associations.

\section{N A Alli}

Department of Molecular Medicine and Haematology, Faculty of Health Sciences, University of the Witwatersrand and National Health Laboratory Service, Johannesburg, South Africa nazeer.alli@nhls.ac.za

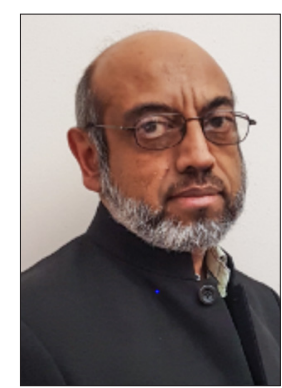

\section{Patel}

Clinical Haematology Unit, Department of Medicine, Chris Hani Baragwanath Academic Hospital and Faculty of Health Sciences, University of the Witwatersrand, Johannesburg, South Africa

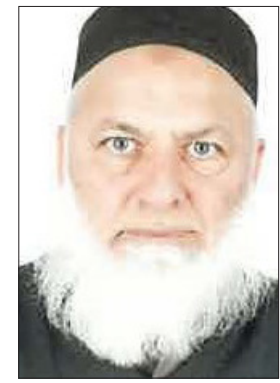

Modell B, Darlison M. Bull World Health Organ 2008;86(6):417-496. https://doi.org/10.2471/ BLT.06.036673

2. Alli NA, Patel M, Poole J, Goga Y, Krause A. Thalassaemia (part 1). S Afr Med J 2021;111(6):529-534. https://doi.org/10.7196/SAMJ.2021.v111i6.15724

S Afr Med J 2021;111(6):528. https://doi.org/10.7196/SAMJ.2021.v111i6.15717 